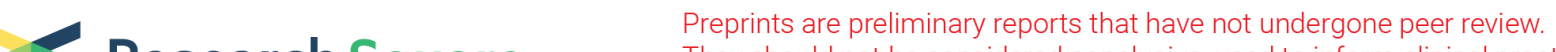 Research Square
Thr ef should not be considered conclusive, used to inform clinical practice,
of the media as validated information.
}

\section{Dietary Moutan Cortex Radicis Alters Serum Antioxidant Capacity, Intestinal Immunity and Colonic Microbiota in Weaned Piglets}

\section{Miaomiao Bai}

Institute of Subtropical Agriculture Chinese Academy of Sciences

Hongnan Liu ( $\sim$ liuhn@isa.ac.cn)

Institute of Subtropical Agriculture Chinese Academy of Sciences https://orcid.org/0000-0002-57108624

\section{Shanshan Wang}

Institute of Subtropical Agriculture Chinese Academy of Sciences

\section{Qingyan Shu}

Institute of Botany Chinese Academy of Sciences

\section{Kang Xu}

Institute of Subtropical Agriculture Chinese Academy of Sciences

Jian Zhou

Institute of Subtropical Agriculture Chinese Academy of Sciences

\section{Xia Xiong}

Institute of Subtropical Agriculture Chinese Academy of Sciences

\section{Ruilin Huang}

Institute of Subtropical Agriculture Chinese Academy of Sciences

Jinping Deng

South China Agricultural University

\section{Yulong Yin}

Institute of Subtropical Agriculture Chinese Academy of Sciences

zheng'an Liu

Institute of Botany Chinese Academy of Sciences

\section{Research}

Keywords: Moutan cortex radicis, Antioxidant capacity, Intestinal microbiota, NF-kB, Weaned piglets

Posted Date: October 23rd, 2020

DOI: https://doi.org/10.21203/rs.3.rs-95711/v1 
License: (c) (i) This work is licensed under a Creative Commons Attribution 4.0 International License. Read Full License 


\section{Abstract}

Background: Moutan cortex radicis (MCR), as a common traditional Chinese medicine, has been widely used as antipyretic, antiseptic and anti-inflammatory agent in China. However, few studies have evaluated the positive effects of MCR, as a new feed additives, on alleviating weaning stress and improving intestinal health and microbiom in pigs. This study aimed to investigate the effect of dietary MCR supplementation on serum antioxidant capacity, intestinal morphology, anti-inflammatory mechanism, and microbiota in weaned piglets.

Results: Supplemental $2000 \mathrm{mg} / \mathrm{kg}$ and $4000 \mathrm{mg} / \mathrm{kg} \mathrm{MCR}$ increased $(P<0.05)$ the final body weight, ADG and ADFI of weaned piglets, and $2000 \mathrm{mg} / \mathrm{kg} \mathrm{MCR} \mathrm{diet} \mathrm{significantly} \mathrm{decreased}(P<0.05)$ the F/G ratio and increased $(P<0.05)$ serum catalase activity compared with CON group. Also, the villus height and crypt depth in the ileum and the concentrations of total SCFA, acetic acid, butyric acid and valeric acid in the colonic contents were higher $(P<0.05)$ in the $2000 \mathrm{mg} / \mathrm{kg}$ and $4000 \mathrm{mg} / \mathrm{kg} \mathrm{MCR}$ diets than CON group. Dietary MCR supplementation at $4000 \mathrm{mg} / \mathrm{kg}$ MCR significantly increased $(P<0.05)$ total antioxidative capability and the crypt depth in the jejunum but decreased $(P<0.05)$ the mRNA expression levels of Interferon $\gamma$, tumor necrosis factor-a, interleukin- $\beta$, inhibiting kappa $B$ kinase $\beta$ (IKK $\beta$ ), inhibiting nuclear factor kappa-B (IкBa) and nuclear factor kappa-B (NF-KB) in the jejunum and ileum.

Supplemental $8000 \mathrm{mg} / \mathrm{kg} \mathrm{MCR}$ had the higher total antioxidative capability and catalase activity in the serum but decreased $(P<0.05)$ the villus height and crypt depth in the jejunum compared with the CON group. MCR addition reduced $(P<0.05)$ serum malondialdehyde content, and tended to increase the mRNA expression of zonula occludens- 1 in the ileum $(P=0.066)$ compared to the CON group. Microbiota sequencing identified the microbial richness indices (Chao1, ACE, and observed species), the relative abundances of Firmicutes and Lactobacillus were increased $(P<0.05)$, and the relative abundances of Bacteroides, Parabacteroides, unidentified_Lachnospiraceae and Enterococcus were reduced $(P<0.05)$ by MCR supplemented. Microbial metabolic phenotypes analysis also showed that the richness of aerobic bacteria and facultative anaerobic bacteria, oxidative stress tolerance, and biofilm forming were significantly increased $(P<0.05)$, and the richness of anaerobic bacteria and pathogenic potential of gut microbiota were reduced $(P<0.05)$ by MCR treatment.

Conclusions: In antibiotic-free diets, MCR supplementation improved growth performance and serum antioxidant capacity, alleviated intestinal inflammatory by inhibiting IKK $\beta / \mathrm{KKBa} / \mathrm{NF}-\mathrm{KB}$ signaling pathway and affecting intestinal microbiota in weaned piglets.

\section{Background}

Oxidative stress often causes mammalian tissues cells damage, especially the intestinal, which significantly affects health status and decrease performance $[1,2]$. Various challenges, such as changes in feed nutrition and environment, pathogenic micro-organisms as well as vaccine and drugs use, induces oxidative stress for weaning piglets [3]. Including weaning stress, these combined stresses result in a decrease in food intake, impaired intestinal barrier function, and disordered intestinal flora, which 
contribute to damaging immune function and increasing the susceptibility to disease [4, 5]. Antioxidative enzymes forming an antioxidative defense system protect the body against reactive oxygen species (ROS) overproduction. Besides, oxidative stress and inflammation are closely related. Cytokines are activated and secreted when the systemic inflammatory incidences. The activation of nuclear factor kappa-B (NF-KB), a transcription factor, can promote the pro-inflammatory cytokines expression [6]. Antibiotics have been used as growth promoters and immune enhancers at subtherapeutic levels in feed for many years. However, in recent years, the reduction or removal of dietary antibiotics has become a developing tendency in swine production [7]. Therefore, finding effective and safe feed additives to be instead of antibiotics is a strong demand for the swine industry. Traditional Chinese medicine is a natural substance, safe, and reliable with little toxicity [8]. Due to the extensive antibacterial and synergistic effects, traditional Chinese medicine has no drug resistance and overcomes the shortcomings of antibiotics.

Moutan cortex radicis (MCR) from the tree peony (Paeonia suffruticosa), commonly known as Mu Dan Pi, is a traditional Chinese medicine commonly used for anti-inflammatory, analgesic, antispasmodic and anti-oxidation properties $[9,10]$. Traditionally, MCR has the clearing heat, promoting blood circulation and removing blood stasis effects on alleviating sickness in humans. Previous researches have demonstrated that MCR has potent free radicals and superoxide anion radicals scavenging capacity, and inhibits ROS production for alleviating oxidative stress $[11,12]$. MCR is rich in various chemical components, including paeonol, paeoniflorin, oxypaeoniflorin, galloylpaeoniflorin, gallic acid, and so on [13]. Paeonol is known to be the main active ingredient, which is reported to inhibit blood coagulation and platelet aggregation for enhancing blood circulation [14], and reduce the production of pro-inflammatory cytokines [15]. Moreover, MCR and its bioactive components have also been reported to alleviate obesity, diabetes, and inflammation $[16,17]$. Previous studies showed that in neuro-inflammatory therapy, paeonol inhibited IKBa to suppress the translocation of NF-KB and decrease the release of pro-inflammatory products [18]. In addition, gut microbiota are the important contributor to animal health and growth such as nutritional conversion, immunity, and intestinal mucosal barrier function [19]. However, the positive effect of MCR on weaning stress, inflammatory response, and gut microbiota composition of weaned piglets have not been reported. In the present study, the effects of dietary MCR on growth performance, serum antioxidant indexes, intestinal morphology and anti-inflammatory response, and gut microbiota composition in weaned piglets were explored for the first time.

\section{Materials And Methods}

The animal protocols and care standards of this experiment were accepted and approved by the Committee of Animal Care and Use of the Institute of Subtropical Agriculture, Chinese Academy of Science (Changsha, CAS20190409).

\section{Animals, experimental design and sample collection}


Thirty-two Duroc $\times$ Large White $\times$ Landrace piglets (castrated male), weaned at an age of $21 \mathrm{~d}$, were allocated randomly into four dietary treatments based on an average initial body weight of $6.37 \pm 0.10 \mathrm{~kg}$. Each treatment had eight replicates with one piglet each, and each replicate were assigned into an individual pen. Before starting the study, all piglets were adaptated for 3-days and fed a basal diet (cornsoybean meal). Four groups included a basal diet (control, CON), the basal diet $+2000 \mathrm{mg} / \mathrm{kg}$ Moutan cortex radicis (LMC), the basal diet $+4000 \mathrm{mg} / \mathrm{kg}$ Moutan cortex radicis (MMC) and the basal diet + $8000 \mathrm{mg} / \mathrm{kg}$ Moutan cortex radicis (HMC). This experiment lasted for $21 \mathrm{~d}$, and all piglets had unlimited access to feed and water. The formulation of basal diet was to meet the NRC (2012) requirements [20] for growing pigs (Table 1) without antibiotics. Moutan cortex radicis was provided by the Institute of Botany, Chinese Academy of Sciences (Beijing, China). 
Table 1

Composition and calculated nutrient levels of the basal diet (air-dry basis)

\section{Items}

Ingredients $(\mathrm{g} / \mathrm{kg})$

Corn $(4.52 \%$ crude protein)

Soybean meal ( $43 \%$ crude protein)

Rice bran meal

Puffing maize powder

broken

Fish meal

Sucrose

Calcium lactate

Zinc oxide

Acidifier

Limestone

Monocalcium phosphate

Antioxidants

Lysine (98\%)

Methionine

Threonine

Vitamin premix $^{1}$

Mineral premix ${ }^{1}$

Total

Nutrient content ${ }^{2}$

Digestible energy $(\mathrm{kcal} / \mathrm{kg})$
Content

570.0

220.0

50.0

50.0

50.0

20.0

10.0

3.00

2.00

4.00

2.20

10.0

1.50

4.00

1.00

1.00

0.30

1.00

1000

3274.5

${ }^{1}$ Provided per kilogram of diet: vitamin $A, 80,000$ IU; vitamin $D_{3}, 20,000$ IU; vitamin $E, 300$ mg; vitamin $\mathrm{K}, 30 \mathrm{mg}$; vitamin $\mathrm{B}_{1}, 30 \mathrm{mg}$; vitamin $\mathrm{B}_{2}, 60 \mathrm{mg}$; vitamin $\mathrm{B}_{6}, 30 \mathrm{mg}$; biotin, $0.2 \mathrm{mg}$; folic acid, $10 \mathrm{mg}$; niacin, $300 \mathrm{mg}$; pantothenic acid, $300 \mathrm{mg} ; \mathrm{Cu}\left(\mathrm{CuSO}_{4} \cdot 5 \mathrm{H}_{2} \mathrm{O}\right), 12 \mathrm{mg} ; \mathrm{Fe}\left(\mathrm{FeSO}_{4} \cdot 7 \mathrm{H}_{2} \mathrm{O}\right), 150 \mathrm{mg} ; \mathrm{Mn}$ $\left(\mathrm{MnSO}_{4} \cdot \mathrm{H}_{2} \mathrm{O}\right), 5 \mathrm{mg} ; \mathrm{Se}\left(\mathrm{NaSeO}_{3}\right), 0.45 \mathrm{mg} ; \mathrm{Zn}(\mathrm{ZnO}), 150 \mathrm{mg}$.

${ }^{2}$ Based on the composition of ingredients provided by the NRC (2012). 


\begin{tabular}{|c|c|}
\hline Items & Content \\
\hline Crude protein (\%) & 17.10 \\
\hline Calcium (\%) & 0.43 \\
\hline Total phosphorus (\%) & 0.63 \\
\hline Available phosphorus (\%) & 0.36 \\
\hline Lysine (\%) & 1.22 \\
\hline Methionine (\%) & 0.38 \\
\hline Methionine + cysteine (\%) & 0.66 \\
\hline \multicolumn{2}{|c|}{$\begin{array}{l}1 \text { Provided per kilogram of diet: vitamin } \mathrm{A}, 80,000 \mathrm{IU} \text {; vitamin } \mathrm{D}_{3}, 20,000 \mathrm{IU} \text {; vitamin } \mathrm{E}, 300 \mathrm{mg} \text {; vitamin } \\
\mathrm{K}, 30 \mathrm{mg} \text {; vitamin } \mathrm{B}_{1}, 30 \mathrm{mg} \text {; vitamin } \mathrm{B}_{2}, 60 \mathrm{mg} \text {; vitamin } \mathrm{B}_{6}, 30 \mathrm{mg} \text {; biotin, } 0.2 \mathrm{mg} \text {; folic acid, } 10 \mathrm{mg} \text {; } \\
\text { niacin, } 300 \mathrm{mg} \text {; pantothenic acid, } 300 \mathrm{mg} ; \mathrm{Cu}\left(\mathrm{CuSO}_{4} \cdot 5 \mathrm{H}_{2} \mathrm{O}\right), 12 \mathrm{mg} ; \mathrm{Fe}\left(\mathrm{FeSO}_{4} .7 \mathrm{H}_{2} \mathrm{O}\right), 150 \mathrm{mg} ; \mathrm{Mn} \\
\left(\mathrm{MnSO}_{4} \cdot \mathrm{H}_{2} \mathrm{O}\right), 5 \mathrm{mg} \text {; } \mathrm{Se}\left(\mathrm{NaSeO}_{3}\right), 0.45 \mathrm{mg} ; \mathrm{Zn}(\mathrm{ZnO}), 150 \mathrm{mg} \text {. }\end{array}$} \\
\hline${ }^{2}$ Based on the compositic & \\
\hline
\end{tabular}

The initial and final body weights, and feed intake were weighted and recorded throughout the experimental stage. The average daily weight gain (ADG), average daily feed intake (ADFI) and $F / G$ ratio were determined. On day 22, twenty-four piglets (8 piglets per treatment group) were stunned (250V, 0.5A, for $5 \sim 6 \mathrm{~s}$ ) and killed. Blood samples were collected from precaval vein and kept into vacuum tubes at room temperature for $2 \mathrm{~h}$. Serum was obtained from the supernatant of blood after centrifugation at $3500 \times \mathrm{g}$ for 15 minutes, and then stored at $-20^{\circ} \mathrm{C}$ for further analysis. Approximately $2 \mathrm{~cm}$ in length segments of duodenum and jejunum were stored in $4 \%$ phosphate-buffered paraformaldehyde $(\mathrm{pH} 7.6)$ for histological analysis. Other middle intestinal samples flushed with $0.9 \%$ ice-cold physiological saline were immediately frozen in liquid nitrogen and stored at $-80^{\circ} \mathrm{C}$ for molecular analysis. Colonic contents were collected for short-chain fatty acids (SCFAs) measurement; one sample of colonic content was allocated for microbiota composition determination.

\section{Detection of Serum Oxidative stress indexes}

The serum contents of total antioxidative capability (T-AOC), glutathione peroxidase (GSH-Px), superoxide dismutase (SOD), catalase (CAT) and malondialdehyde (MDA) were evaluated by previous evaluation procedures [21], and by spectrophotometric kits (Nanjing Jiangcheng Biotechnology Institute, Nanjing, China).

\section{Assessment of Intestinal morphology}

The method of Histological hematoxylin eosin (HE) staining, as previously described, was used to evaluate intestinal histomorphological changes [22]. In brief, the middle sections of jejunum and ileum were embedded in paraffin after removed from fixation fluid and dehydrated, and made into 
approximately $5 \mu \mathrm{m}$ thickness transverse sections, then stained with HE. Villus height $(\mathrm{VH})$ and crypt depth (CD) were measured by a computer-assisted microscopy (Leica DMI3000B microscopy, Switzerland, Germany). Morphological indices were measured from ten microscopic fields at $100 \times$ magnification. The ratio of villus height to crypt depth (VH/CD) was calculated and analyzed.

\section{Analysis of mRNA expression}

The extraction process of total RNA from intestinal tissues was followed by the description of Xiong et al. (2015) [23]. Briefly, samples were homogenized in the Trizol Reagent (Invitrogen, Carlsbad, CA, USA) for total RNA extraction, then further purified with the RNeasy kit (Eppendorf AG, Hamburg, Germany). In the $10 \mathrm{ul}$ reaction systems, $1.0 \mu \mathrm{g}$ of total RNA was incubated with DNase I for synthetising first-strand cDNA. Then reverse- transcription using Oligo (dT) primers (Takara, Otsu, Japan) was further to synthesise the double-strand cDNA. Real-time PCR was performed with SYBR Green Master Mix reagent (Takara, Otsu, Japan) and objective gene primer pairs using the LightCycler ${ }^{\circledR} 480$ Real-Time PCR System (Roche, Switzerland, Germany). Primer 6.0 software was used to design primers of the $\beta$-actin housekeeping gene and target genes (Table 2). The fold changes in target genes was determined using the $2^{-\Delta \Delta C t}$ method. 
Table 2

Primers used for quantitative real-time polymerase chain reaction

\begin{tabular}{|c|c|c|c|c|}
\hline Gene & Accession No. & Primer, 5'-3' & Size (bp) & $\mathrm{T}_{\mathrm{A}}\left({ }^{\circ} \mathrm{C}\right)$ \\
\hline \multirow[t]{2}{*}{$\beta$-actin } & XM_021086047.1 & F: CTGCGGCATCCACGAAACT & 147 & 61 \\
\hline & & R: AGGGCCGTGATCTCCTTCTG & & \\
\hline \multirow[t]{2}{*}{ IFN-Y } & NM_213948.1 & F: GCCATTCAAAGGAGCATGGA & 144 & 58 \\
\hline & & R: TTCACTGATGGCTTTGCGCT & & \\
\hline \multirow[t]{2}{*}{ TNF-a } & NM_214022.1 & F: CCCCTGTGAGGGCAGGA & 185 & 60 \\
\hline & & R: CAGGCCACACATCCCTGAAT & & \\
\hline \multirow[t]{2}{*}{ IL-1 $\beta$} & NM_214055.1 & F: CCTGAGATTGATGCCGTCCA & 267 & 60 \\
\hline & & R: TCTTCAAGCCGTGTAGCCAT & & \\
\hline \multirow[t]{2}{*}{ IL-6 } & NM_214399.1 & F: CCTGAGATTGATGCCGTCCA & 267 & 59 \\
\hline & & R: TCTTCAAGCCGTGTAGCCAT & & \\
\hline \multirow[t]{2}{*}{ Claudin-1 } & NM_001244539.1 & F: AAGGACAAAACCGTGTGGGA & 247 & 60 \\
\hline & & R: CTCTCCCCACATTCGAGATGATT & & \\
\hline \multirow[t]{2}{*}{ Occludin } & NM_001163647.2 & F:ACGAGCTGGAGGAAGACTGGATC & 238 & 60 \\
\hline & & R:CCCTTAACTTGCTTCAGTCTATTG & & \\
\hline \multirow[t]{2}{*}{ ZO-1 } & XM_021098896.1 & F: ССТGСTTCTCCAАAААСТСТT & 252 & 60 \\
\hline & & R: TTCTATGGAGCTCAACACCC & & \\
\hline \multirow[t]{2}{*}{ IKK $\beta$} & NM_001099935.1 & F: GTGACATCGCCTCTGCACTT & 81 & 59 \\
\hline & & R: GCAGGACGATGTTTTCTGGC & & \\
\hline \multirow[t]{2}{*}{ IKBa } & XM_001924394.6 & F: CACCCGAGTTAGAAGGGCTC & 155 & 59 \\
\hline & & R: GGTATCTGCTGAGGTGTGCTG & & \\
\hline \multirow[t]{2}{*}{ NF-KB } & NM_001048232.1 & F: AGCCATTGACGTGATCCAGG & 248 & 60 \\
\hline & & R: CGAAATCGTGGGGCACTTTG & & \\
\hline \multicolumn{5}{|c|}{$\begin{array}{l}\mathrm{T}_{\mathrm{A}} \text {, annealing temperature; IFN- } \gamma \text {, Interferon } \gamma \text {; TNF-a, tumor necrosis factor- }-\mathrm{a} \text {; IL- } 1 \beta \text {, interleukin- } 1 \beta ; \text { IL-6 } \\
\text { interleukin-6; ZO-1 = zonula occludens- } 1 \text {; IKK } \beta \text {, inhibiting kappa B kinase } \beta ; \text { IKBa, inhibiting nuclear } \\
\text { factor kappa-B; NF-KB, nuclear factor kappa-B. }\end{array}$} \\
\hline
\end{tabular}

Each group selected six samples of colonic contents ( $n=6$ per group) for microbiota analysis. According to manufacturer's instruction, total microbiota DNA was extracted using PowerFecal ${ }^{\mathrm{TM}}$ DNA Isolation kit 
(MO BIO Laboratories, Carlsbad, CA, USA). The Novogene Bioinformatics Technology Co., Ltd was invited to complete the $16 \mathrm{~S}$ rRNA gene sequencing. Under the PCR reaction procedure: $94{ }^{\circ} \mathrm{C}$ for 3 min ( 1 cycle), $94{ }^{\circ} \mathrm{C}$ for $45 \mathrm{~s} / 50{ }^{\circ} \mathrm{C}$ for $60 \mathrm{~s} / 72{ }^{\circ} \mathrm{C}$ for $90 \mathrm{~s}$ (35 cycles), and a last step of $72{ }^{\circ} \mathrm{C}$ for $10 \mathrm{~min}, \mathrm{PCR}$ products of pigs' samples were obtained using phusion high-fidelity PCR Mastermix (New England Biolabs (Beijing) LTD., China), then purified by using the QIAquick Gel Extraction Kit (QIAGEN, Dusseldorf, Germany). Sequencing libraries were generated using TruSeq ${ }^{\circledR}$ DNA PCR-Free Sample Preparation Kit (Illumina, USA), which subseauently enriched the manufacturer's recommendations and index codes. The evaluation of library quality was done on the Qubit@2.0 Fluorometer (Thermo Sciencetific) and Agilent Bioanalyzer 2100 system. Finally, an Illumina MiSeq $2 \times 250$ platform was used to performe the library sequencing for generating 250 bp paired-end reads by the following protocols described by Caporaso, et al (2012) [24]. FLASH, as a very fast and accurate analysis tool, merged paired-end reads from the original DNA fragments, and then identified each sample based on the unique barcodes [25]. To mine deeper data of microbial diversity of the differences between the samples, significance test were conducted with some statistical analysis methods, including T-test, MetaStat, linear discriminant analysis effect size (LEfSe), Anosim and multi-response permutation procedure (MRPP). Evaluation of the correlation between the gut microbiota and other dimensions was frequently performed with the Spearman's rank correlation test.

\section{Microbiological function and phenotypic prediction}

Based on metagenomic 16S rRNA data, Tax4Fun, as a software package, was used for predicting functional profiles [26]. Tax4Fun could perform a mapping of 16 rRNA gene sequences reads to SILVA labeled OUT abundances. Normalized Taxonomic abundances are used to linearly combine the precomputed functional profiles of the KEGG organisms for predicting the microbial functional profile. Bugbase is a tool for measuring high-level phenotypes in the colonic microbiota using 16S RNA datasets and mapping file [27]. Besides, the Spearman correlation analysis between colonic microbiota and metabolites was performed in R software (v3.2.1).

\section{Short-chain fatty acids (SCFAs) composition of colonic contents}

The composition of SCFAs in the colonic contents was determined according to the method described by Kong et al. (2016) [28]. About $1.0 \mathrm{~g}$ of the fresh colonic contents were mixed thoroughly with $5 \mathrm{~mL}$ distilled water in a centrifuge tube, incubated and shaken $30 \mathrm{~min}$, and centrifuged at $10000 \times \mathrm{g}, 10 \mathrm{~min}$ at $4{ }^{\circ} \mathrm{C}$. After transferring the supernatant into a new centrifuge tube, the precipitate was repeatedly extracted twice with $2 \mathrm{~mL}$ distilled water. Mix all supernatants $(0.9 \mathrm{~mL})$ with $25 \%$ metaphosphoric acid solution $(0.1 \mathrm{~mL})$ for $3 \sim 4 \mathrm{~h}$ at room temperature, then centrifuge at $10000 \times \mathrm{g}$ for $10 \mathrm{~min}$ at $4{ }^{\circ} \mathrm{C}$. After filtered through a $0.45-\mu \mathrm{m}$ polysulfone filter, the supernatant portion was subjected for analyses on Agilent 6890 gas chromatography (Agilent Technologies, Inc, Palo Alto, CA, USA). The standard solutions of acetic, propionic, butyric, isobutyric, valeric and isopentanoic acids were prepared at concentrations of $5,10,15,20$ and $25 \mathrm{mmol} / \mathrm{L}$. 


\section{Statistical analysis}

All statistical analysis were performed using IBM SPSS 22.0 software (SPSS Inc, Chicago, IL, USA) except for microbiome analysis. One-way ANOVA and Tukey-Kramer multiple comparison tests were used to compare the differences among experimental treatments. After nonparametric tests, the 16 rRNA sequencing data were analyzed by a Kruskal-Wallis analysis to det ermine significant differences. The differences were declared significant at $P<0.05$ and a trend at $0.05<P \leq 0.10$ in all analyses. Results are expressed as means \pm standard errors (SEM) unless otherwise noted.

\section{Results}

\section{Growth performance}

As shown in Table 3, the initial body weight of pigs had no significant differences among the treatments $(P>0.05)$. Compared to the $C O N$ and HMC groups, the final body weight, ADG, and ADFI were significantly increased in $L M C$ and $M M C$ groups $(P<0.05)$. And then, $L M C$ significantly reduced the $F / G$ ratio compared with the CON group $(P<0.05)$.

Table 3

Effects of dietary Moutan cortex radicis on the growth performance in growing pigs.

\begin{tabular}{|c|c|c|c|c|c|}
\hline \multirow[t]{2}{*}{ Item } & \multicolumn{4}{|l|}{ Diets $^{1}$} & \multirow[t]{2}{*}{$P$-value } \\
\hline & CON & LMC & MMC & HMC & \\
\hline Initial body weight, kg & $6.10 \pm 0.21$ & $6.07 \pm 0.18$ & $6.10 \pm 0.18$ & $6.11 \pm 0.17$ & 0.999 \\
\hline Final body weight, kg & $7.93 \pm 0.37^{a}$ & $11.84 \pm 0.68^{b}$ & $12.51 \pm 0.6^{b}$ & $8.03 \pm 0.65^{a}$ & $<0.01$ \\
\hline$A D G, k g / d$ & $0.08 \pm 0.01^{a}$ & $0.24 \pm 0.02^{b}$ & $0.28 \pm 0.04^{b}$ & $0.11 \pm 0.02^{\mathrm{a}}$ & $<0.01$ \\
\hline ADFI, $\mathrm{kg} / \mathrm{d}$ & $0.29 \pm 0.04^{a}$ & $0.41 \pm 0.03^{b}$ & $0.42 \pm 0.04^{b}$ & $0.28 \pm 0.04^{a}$ & $<0.01$ \\
\hline $\mathrm{F} / \mathrm{G}$ ratio & $3.29 \pm 0.29^{b}$ & $1.72 \pm 0.07^{a}$ & $2.44 \pm 0.78^{a b}$ & $2.72 \pm 0.47^{a b}$ & 0.039 \\
\hline \multicolumn{6}{|c|}{$\begin{array}{l}{ }^{1} \mathrm{CON} \text {, control group, basal diet without antibiotics; LMC, the control diet }+2000 \mathrm{mg} / \mathrm{kg} \text { Moutan cortex } \\
\text { radicis; MMC, the control diet }+4000 \mathrm{mg} / \mathrm{kg} \text { Moutan cortex radicis, HMC, the control diet + } \\
8000 \mathrm{mg} / \mathrm{kg} \text { Moutan cortex radicis. }\end{array}$} \\
\hline \multicolumn{6}{|c|}{$\begin{array}{l}\text { Data are expressed as means } \pm \text { SEM }(n=8) \text {. Means within a row with different superscripts are } \\
\text { significantly different }(P<0.05) \text {. }\end{array}$} \\
\hline
\end{tabular}

\section{Serum antioxidant indexes}

As shown in Table 4, pigs fed the MMC and HMC diets had higher T-AOC activity $(P<0.05)$ compared with the CON and LMC groups. The higher CAT activity $(P<0.05)$ was observed in LMC and HMC pigs compared with CON group. Compared to the MMC group, HMC had a higher CAT activity $(P<0.05)$ in the 
serum. Pig fed the CON diet had the highest GSH-Px activity $(P<0.05)$ and MDA concentration $(P<0.05)$ in the serum compared with that of the pigs fed the LMC, MMC, and HMC diets. There was no significant effect of dietary MCR on SOD activity $(P>0.05)$.

Table 4

Effects of dietary Moutan cortex radicis on serum antioxidant indexes in growing pigs.

\begin{tabular}{|llllll|}
\hline \multirow{2}{*}{ Item $^{2}$} & \multicolumn{2}{c}{ Diets $^{1}$} & & P-value \\
\cline { 2 - 5 } & CON & LMC & MMC & HMC & \\
\hline T-AOC, $U / m L$ & $1.96 \pm 0.20^{\mathrm{a}}$ & $1.85 \pm 0.08^{\mathrm{a}}$ & $3.28 \pm 0.25^{\mathrm{b}}$ & $3.72 \pm 0.26^{\mathrm{b}}$ & $<0.01$ \\
\hline $\mathrm{CAT}, \mathrm{U} / \mathrm{mL}$ & $23.06 \pm 2.45^{\mathrm{a}}$ & $38.94 \pm 3.89^{\mathrm{bc}}$ & $32.42 \pm 2.92^{\mathrm{ab}}$ & $54.47 \pm 5.06^{\mathrm{c}}$ & $<0.01$ \\
\hline $\mathrm{SOD}, \mathrm{U} / \mathrm{mL}$ & $40.44 \pm 1.88$ & $48.94 \pm 1.68$ & $50.50 \pm 4.87$ & $52.22 \pm 5.25$ & 0.184 \\
\hline $\mathrm{GSH}-\mathrm{Px}, \mathrm{U} / \mathrm{mL}$ & $1238.78 \pm$ & $933.63 \pm$ & $946.55 \pm$ & $934.80 \pm 54.35^{\mathrm{a}}$ & $<0.01$ \\
\hline $\begin{array}{l}\mathrm{MDA}, \\
\mathrm{nmol} / \mathrm{mL}\end{array}$ & $39.91^{\mathrm{b}}$ & $52.70^{\mathrm{a}}$ & $89.92^{\mathrm{a}}$ & & \\
\hline
\end{tabular}

${ }^{1}$ CON, control group, basal diet without antibiotics; LMC, the control diet $+2000 \mathrm{mg} / \mathrm{kg}$ Moutan cortex radicis; MMC, the control diet $+4000 \mathrm{mg} / \mathrm{kg}$ Moutan cortex radicis, HMC, the control diet + $8000 \mathrm{mg} / \mathrm{kg}$ Moutan cortex radicis.

${ }^{2}$ T-AOC, total antioxidant capacity; CAT, catalase; SOD, superoxide dismutase; GSH-Px, glutathione peroxidase; MDA, malondialdehyde.

Data are expressed as means \pm SEM $(n=8)$. Means within a row with different superscripts are significantly different $(P<0.05)$.

\section{Jejunal and ileal morphology}

The effects of MCR on jejunal and ileal morphology in the pigs are shown in Table 5 and Fig. 1. Compared with the CON and HMC groups, MMC significantly increased the $\mathrm{CD}(P<0.05)$ in the jejunum. The LMC diet increased the ratio of $\mathrm{VH} / \mathrm{CD}(P<0.05)$ in the jejunum compared with the MMC diet. Pig fed with the HMC diet had the shortest $\mathrm{VH}(P<0.05)$ compared with that of the pigs fed other three diets. Compared to the CON and HMC diets, LMC and MMC diets markedly increased $(P<0.05)$ the $\mathrm{VH}$ and $\mathrm{CD}$ in the ileum. 
Table 5

Effects of dietary Moutan cortex radicis on on the morphology of the jejunum and ileum of growing pigs.

Item

Diets $^{1}$

$P$-value

CON LMC MMC HMC

Jejunum

Villus height, $\mu \mathrm{m}$

$370.13 \pm$

$382.23 \pm$

$372.27 \pm$

$340.50 \pm$

$<0.01$

$9.21^{\mathrm{b}}$

$9.92^{\mathrm{b}}$

$8.58^{\mathrm{b}}$

$7.89^{a}$

Crypt depth, $\mu \mathrm{m}$

$200.39 \pm$

$189.56 \pm$

$7.01^{\mathrm{b}}$

$6.53^{\mathrm{ab}}$

$225.77 \pm 6.44^{\mathrm{c}}$

$175.80 \pm$

$<0.01$

Villus height/Crypt depth

$2.00 \pm 0.09^{a b}$

$2.26 \pm 0.11^{b}$

$1.7 \pm 0.08^{a}$

$5.47^{\mathrm{a}}$

lleum

Villus height, $\mu \mathrm{m}$

$312.28 \pm$

$358.50 \pm$

$343.82 \pm$

$323.20 \pm$ $<0.01$

$8.34^{\mathrm{a}}$

$5.29^{\mathrm{b}}$

$14.67^{\mathrm{b}}$

$7.46^{\mathrm{a}}$

Crypt depth, $\mu \mathrm{m}$

$174.49 \pm$

$212.31 \pm$

$6.20^{\mathrm{a}}$

$4.63^{\mathrm{b}}$

$206.47 \pm 5.68^{b}$

$185.63 \pm$

$<0.01$

Villus height/Crypt depth

$1.77 \pm 0.05$

$1.78 \pm 0.04$

$1.82 \pm 0.04$

$5.19^{\mathrm{a}}$

$2.06 \pm 0.08^{a b}<0.01$

${ }^{1}$ CON, control group, basal diet without antibiotics; LMC, the control diet $+2000 \mathrm{mg} / \mathrm{kg}$ Moutan cortex radicis; MMC, the control diet $+4000 \mathrm{mg} / \mathrm{kg}$ Moutan cortex radicis, HMC, the control diet + $8000 \mathrm{mg} / \mathrm{kg}$ Moutan cortex radicis.

Data are expressed as means \pm SEM $(n=8)$. Means within a row with different superscripts are significantly different $(P<0.05)$.

\section{Expression of genes associated with proinflammatory factors, tight junction proteins and NF-KB signaling pathway}

As shown in Fig. 2, HMC group significantly decreased the mRNA expression level of interferon $y$ (IFN-y, $P$ $<0.05$ ) in the jejunum and ileum compared with the CON group. Compared to the CON diet, the MMC diet decreased the mRNA expression level of interleukin-6 $(\mathrm{IL}-6, P<0.05)$ in the jejunum and mRNA expression levels of tumor necrosis factor- $a($ TNF- $a)$ and IL-1 $\beta$ in the ileum $(P<0.05)$. The LMC diet significantly inhibited the mRNA expression level of TNF-a $(P<0.05)$ in the ileum compared with the CON diet, but had the highest mRNA expression level of TNF-a $(P<0.05)$ in the jejunum of pigs among all treatments.

Dietary supplementation of MCR had a significant trend of an inhibited the IL- 6 mRNA expression ( $P=$ $0.054)$. HMC significantly enhanced $(P<0.05)$ the ZO-1 mRNA expression in the jejunum compared with the LMC diet, and increased $(P<0.05)$ the occludin mRNA expression in the ileum compared to the MMC 
diet. And there was a significant trend $(P=0.066)$ toward higher the mRNA expression level of ZO- 1 in the ileum pigs fed MCR diets.

The influences of dietary MCR on the IKKB/IKBa/NF-KB signaling pathway are shown in Fig. $2 \mathrm{C}$. Compared to the CON and HMC diets, LMC and MMC diets significantly inhibited $(P<0.05)$ the expressions of inhibiting kappa $B$ kinase $\beta$ (IKKß) and inhibiting nuclear factor kappa-B (IKBa) in the jejunum. MMC group had a lower $(P<0.05)$ expression level of NF-KB mRNA in the jejunum compared with the HMC group. LMC and MMC had a decreasing tendency for the mRNA expression levels of IKK $\beta$ $(P=0.078)$ and NF-KB $(P=0.064)$ in the ileum compared with CON and HMC groups. Compared to the CON group, MMC also significantly down-regulated the IkBa mRNA expression $(P<0.05)$ in the ileum.

\section{Concentrations of SCFA in the colonic contents}

Analysis of the concentrations of SCFA in the colonic contents revealed differences among all treatments (Fig. 3). The pigs fed the enhanced The concentrations of total SCFA, acetic acid, butyric acid, and valeric acid in the colonic contents were higher in the LMC and MMC groups than in the the CON group $(P<$ 0.05). Also, dietary supplementation of MCR showed a tendency to to increase the concentration of isobutyric acid $(P=0.062)$ in the colonic contents of pigs. The concentrations of propionic acid and isopentanoic acid among the four treatments had no significant difference $(P>0.05)$.

\section{Colonic microbiota diversity and composition}

To better understand the differences in richness, the overlaps among treatments were illustrated using a Venn diagram (Fig. 4A). This analysis showed that CON\&LMC, CON\&MMC and CON\&HMC contained 304, 319 and 361 common OTUs, respectively. As shown in Fig. 4B, the microbial richness indices (Chao1, ACE and observed species) were significantly increased $(P<0.05)$ in the gut microbiota of piglets with Moutan cortex radicis supplementation, whereas no significant differences were found in the diversity indices (Shannon and Simpson) of gut microbiota. The principal coordinate analysis (PCoA, Fig. 4C) and nonmetric multidimensional scaling (NMDS, Fig. 4D) analysis of $\beta$-diversity showed a strong difference in the microbiota from the control group to Moutan cortex radicis-treated groups. An unweighted Unifrac cluster tree based on the unweighted pair-group method with arithmetic mean (UPGMA) analysis showed the similarity and phylogeny of all observed samples at the phylum level (Fig. 4E), and Firmicutes, Bacteroidetes and Proteobacteria are the dominant bacteria in pigs' colonic microbiota. Further, MetaStat analysis of the microbial community was to explore the significant differences in microbial composition between the MCR-treated group and the control group (Fig. 4F). MCR supplementation significantly elevated the relative abundance of Tenericutes, and decreased the relative abundance of Bacteroidetes in the colonic microbiota.

As shown in Fig. 5, the phylum level analysis showed that dietary supplementation of MCR significantly increased the relative abundance of Firmicutes $(P<0.05)$ and decreased the relative abundance of Bacteroidetes $(P<0.05)$. In the genus level, MCR treatment significantly decreased the relative abundances of Bacteroides, Parabacteroides, unidentified_Lachnospiraceae, and Enterococcus in the

Page 14/30 
colonic microbiota $(P<0.05)$. Compared to the CON group, LMC and MMC groups increased $(P<0.05)$ the relative abundance of Lactobacillus.

\section{Metabolic functions and phenotypes of colonic microbiota}

Tax4Fun was performed to determine the effects on metabolic functions of gut microbiota by MCR treatment. Based on KEGG annotation results, the principal components analysis (PCA) showed that the microbiotal metabolic functions were significantly separated in the CON group and MCR-treated groups (Fig. 6A). As shown in Fig. 6B, KEGG pathways associated with microbial metabolism at level 3, including mismatch repair, pyruvate and purine metabolism, DNA repair and recombination protein, were upregulated by dietary MCR-treated. Galactose metabolism, oxidative phosphorylation and amino acidrelated enzymes were significantly down-regulated. Moreover, based on 16S OTU results to predict bacterial phenotype database, Bugbase can be analyzed the differences among groups simultaneously. Results showed that MCR diet significantly increased $(P<0.05)$ the aerobic bacterial richness, and oxidative stress tolerance and biofilm forming of colonic microbiota compared to the CON group. The richness of Gram-positive bacteria showed a marked increasing trend $(P=0.052)$, while Gram-negative bacteria had a significant decrease trend $(P=0.052)$ by MCR treatments. The pathogenic potential of gut microbiota was reduced $(P<0.05)$ by increasing dietary MCR level. LMC and HMC groups had a lower $(P$ $<0.05)$ richness of anaerobic bacteria and a higher $(P<0.05)$ facultative anaerobic bacteria than the CON group.

Results of Spearman's correlation coefficients between major genera and growth, serum antioxidant parameters makers and colonic SCFA contents were calculated and presented with heatmap (Fig. 7). Lactobacillus and Blautia had significant positive relations with ADG, serum CAT activity, and the contents of total SCFAs, acetic acid, propionic acid, butyric acid and valeric acid $(P<0.05)$, and was negatively related with the $\mathrm{F} / \mathrm{G}$ ratio $(P<0.05)$. Bacteroides showed significant positive relations with serum GSH-Px activity and MDA content, and was negatively correlated with CAT and the contents of total SCFAs, acetic acid, propionic acid, butyric acid and valeric acid $(P<0.05)$. Parabacteroides showed significant positive correlations with serum GSH-Px activity and the $\mathrm{F} / \mathrm{G}$ ratio $(P<0.05)$, and was negatively correlated with CAT and total SCFAs, propionic acid, butyric acid and valeric acid contents $(P<$ 0.05). Unidentified_Lachnospiraceae was positively correlated with $(P<0.05)$ the F/G ratio and GSH-Px activity, and negatively correlated with $(P<0.05)$ serum SOD activity.

\section{Discussion}

In recent years, the misuse of feed antibiotics in the swine industry has seriously threatened human health and food safety, and China has banned the application of antibiotics in feeds in 2020. Therefore, exploring an alternative to antibiotics is necessary for the sustainable development of the livestock industry. Many previous studies have found the positive results of MCR in various animal models of disease [29-31]. In the present study, addition of MCR to the diet without antibiotic firstly showed the effect of promoting growth performance in weaned piglets. The improvement may be due to protecting 
piglets from oxidative stress and intestinal inflammation response caused by weaning stress, which was evidenced by the enhanced antioxidant capacity, inhibition of NF-kB signaling pathway and regulation of intestinal flora structure and metabolites in piglets.

The depletion of intracellular free-radicals and antioxidants inhibited various antioxidant enzymes activities, which induced oxidative stress [32]. The antioxidant mechanism of polyphenols mainly through increasing antioxidant protective barrier and eliminating intracellular ROS to maintain oxidative balance $[33,34]$. Previous studies demonstrated more than $50 \mathrm{ug} / \mathrm{mL}$ of MCR enhanced the antioxidant defense system by improving the activities of GSH and SOD in glucose-induced oxidative damage [35]. In this study, the activities of T-AOC and CAT were improved, and the GSH-Px activity was decreased in weaned piglets supplemented with MCR. Overall, MCR can play an antioxidant role by increasing antioxidant activity. The mechanism of antioxidative stress and anti-inflammation closely connected to the NF-KB signaling pathway in the body $[36,37]$. Dynamic changes of proinflammatory cytokines levels in the intestinal tract tissue act as crucial messengers to stimulate the intestinal inflammatory process. Therefore, during anti-inflammatory therapy, it is necessary to downregulate the production of these proinflammatory cytokines [38]. The phosphorylation and degradation of the NF-KB bound protein IKB, activated by the IKK signaling phosphorylation, are directly involved in the activating NF-KB [39]. As demonstrated in the present study MCR has effectively decreased the cytokine productions in jejunum and ileum via inhibiting IKK $\beta / \mathrm{IKBa} / \mathrm{NF}-\mathrm{KB}$ signaling pathway. At the same time, evidences also found that MCR or paeonol could suppress the gene and protein expression of pro-inflammatory cytokines by blocking NF-KB pathway in the LPS-stimulated inflammatory response $[30,40]$. Thus it could be suggested that MCR has potential in antioxidant and anti-inflammation therapy in weaned piglets.

Enhanced intestinal morphology and gut barrier are closely associated with nutrients absorption and intestinal integrity [41]. Intestinal morphology significantly changes, including villous atrophy and crypt hyperplasia, which will result in diarrhea and growth retardation in pigs [42]. An increasing villus height/crypt depth ratio is one of the most important indexes of intestinal morphology in evaluating the improvement of intestinal function and enhancement of absorption capacity [43]. A recent study found that dietary supplemented with MCR at $2000 \mathrm{mg} / \mathrm{kg}$ improved the ratio of villus height to crypt depth in the jejunum, and increased the villus height and crypt depth in the ileum of weaned piglets. $4000 \mathrm{mg} / \mathrm{kg}$ MCR increased the villus height and crypt depth in the ileum, whereas $8000 \mathrm{mg} / \mathrm{kg}$ MCR decreased the villus height and crypt depth in the jejunum and ileum compared with $2000 \mathrm{mg} / \mathrm{kg}$ and $4000 \mathrm{mg} / \mathrm{kg} \mathrm{MCR}$ groups. Therefore, we speculated that a high dosage $(8000 \mathrm{mg} / \mathrm{kg})$ of MCR does not promote the improvement of intestinal villi and intestinal digestive ability. Tight junctions protein, as the mechanical barrier, constitutes intestinal barrier function and prevents pathogenic antigen invasion [44]. Occludin, claudin-1 and ZO-1 are the main cytoplasmic transmembrane and adaptor protein and jointly constitute the tight intercellular junctions. Improved expression of three crucial proteins can enhance the intestinal barrier function for decreasing permeability of the intestinal wall [45]. Several studies have found that traditional Chinese medicine can alter intestinal permeability dependent on tight junctions protein changes $[46,47]$. Our results also demonstrated that ZO-1 and occludin mRNA expression in jejunum and 
ileum were increased in piglets fed MCR $(8000 \mathrm{mg} / \mathrm{kg}$ feed $)$ diet. This suggests that a high dosage of MCR contributed to improving the intestinal barrier integrity in weaned piglets.

The gut microbiome is a complex microbial ecosystem, whose activities and reciprocal relationship has been essential to the host health and disease [48]. The investigation of the gut microbiome has been described as a biomarker for evaluating the effect of specific dietary components on the host. In the current research, MCR shapes intestinal microbiota in weaned piglets, including increases in the microbial richness, the abundances of the phyla Firmicutes and the genera Lactobacillus, and a decrease in the abundances of the phyla Bacteroidetes, and the genera Bacteroides, Parabacteroides, unidentified_Lachnospiraceae and Enterococcus. Piglets fed MCR diets had a higher observed Chao1, ACE and species number for gut microbiota, which indicates that MCR supplementation contributes to improving microbial diversity. Firmicutes and Bacteroidetes, as two main communities, are associated with the energy metabolism homeostasis [49]. Many previous studies reported that increased Firmicutes and reduced Bacteroidetes are most common in the obesity phenotype, which leaded to effectively absorb the calories from food [50]. The abundance of Lactobacillus in the intestine is closely related to activating the production of secretory IgA for improving intestinal mucosal immunity, which acts an important role in maintaining intestinal barrier function [51]. Bacteroides and Parabacteroides, occurring in the early stages of life, have been reported to produce gamma amino butyric acid, associated with growth [52]. The abundance of Enterococcus correlated positively with metabolites associated with inducing oxidative stress [53]. Moreover, changed microbial composition has been linked to the production and composition of SCFA in the colon. In the present study, we found that colonic contents of SCFA, including acetic acid, propionic acid, butyric acid, and valeric acid, were increased significantly in piglets fed the MCR diet at 2000 and $4000 \mathrm{mg} / \mathrm{kg}$. SCFA, as an important metabolite of gut microbiota, could favor the energy homeostasis, and relieve inflammations and metabolic syndrome in the colon [54]. Corrêa-Oliveira has demonstrated that the addition of SCFA increased villi height and crypt depth, enhanced the intestinal barrier, and had anti-inflammatory properties in mice [55]. In summary, MCR addition regulates piglets' intestinal microbiota and microbial metabolites for improving intestinal health. And it would be interesting to further investigate whether MCR has a marked influence on lipid metabolism through regulating intestinal microbiota in weaned piglets.

Based on microbial function prediction, results demonstrated that MCR addition increased the pyruvate metabolism, DNA repair and purine metabolism, and decreased oxidative phosphorylation and amino acid-related enzymes. MCR may inhibit the amino acid metabolism and promote the nucleotide metabolism and multi-drug resistance in gut microbial communities. Moreover, the changes of microbial metabolic phenotypes in weaned piglets treated with different doses of MCR, were first revealed. Dietary supplementation of MCR has a strong antimicrobial property against Gram-negative and anaerobic bacteria, but promotes the proliferation of Gram-positive and aerobic bacteria. MCR supplementation also increased biofilm forming and oxidative stress tolerance, while the promoting effect was negatively correlated with the added dose. Biofilm formation and oxidative stress tolerance of microbial communities were found to go together with drug resistance, inflammation, and pathogenesis [56]. Higher MCR levels significantly reduced the pathogenic potential of microbial communities. However, these 
metabolic phenotypes changes need to further explore the mechanism. Further, association analysis of growth performance, serum antioxidants, colonic SCFA contents and microbiota first revealed that MCR supplementation has widely influenced the growth and health in piglets.

\section{Conclusions}

In conclusion, dietary supplemented with Moutan cortex radicis was able to significantly alleviate weaning stress in piglets, as demonstrated by improving antioxidant capacity and regulating gut microbial communities. Moutan cortex radicis increased serum antioxidant capacity, improved intestinal barrier function and inhibited the NF-кB signaling pathway. Additionally, besides improving the richness indices, MCR significantly increased the microbial metabolic phenotypes and functions, and metabolites, which is benefit weaned piglets with better intestinal status and growth potential. The present study contributes to provide theoretical support in applicating Moutan cortex radicis at $4000 \mathrm{mg} / \mathrm{kg}$ for antioxidation and regulating intestinal health in livestock production.

\section{Abbreviations}

\section{ADG}

average daily weight gain; ADFl:average daily feed intake; CAT:catalase; CD:crypt depth; GSH-

Px:glutathione peroxidase; HE:hematoxylin eosin; IFN-y:Interferon y; IL-1 $\beta$ :interleukin-1 $\beta$; IL-6:interleukin-6; IKK $\beta$ :inhibiting kappa $B$ kinase $\beta$ :IкBa, inhibiting nuclear factor kappa-B; LEfSe:linear discriminant analysis effect size; MCR:Moutan cortex radicis; MDA:malondialdehyde; NF-kB:nuclear factor kappa-B; MRPP:multi-response permutation procedure; ROS:reactive oxygen species; SCFAs:short-chain fatty acids; SOD:superoxide dismutase; T-AOC:total antioxidative capability; TNF-a:tumor necrosis factor-a; VH:villus height; ZO-1:zonula occludens-1.

\section{Declarations}

\section{Acknowledgments}

Not applicable.

\section{Author's contributions}

The contributions of the authors were as follows: M. B. conducted the animal work, sample analysis and manuscript writing; H. L., J. D., Y. Y., and Q. S. designed the research and reviewed the manuscript; K. X, X. X. and R. H analyzed the data and helped to revise the manuscript. S. Liu and Q. S. provided experimental materials and analyzed study data. S. W. and J. Z. helped to conduct animal trial and sample analysis. All authors read and approved the final manuscript.

\section{Funding}


The project was supported by grant from was supported by grant from National Natural Science Foundation of China (32072741), the Innovation Team in Key Area" Innovation Team of Physiology and Metabolism and Body Health in Pig (2019RS3022), Science and technology program of Changsha (kq1907074). The research was also funded by the research program of Huxiang Youth Talent Program of Hunan Province (2018RS3110), Youth Innovation Promotion Association, CAS (2019356), and the China Agriculture Research System (CARS-35).

\section{Availability of data and materials}

All data generated or analyzed during this study are available from the corresponding author upon reasonable request.

\section{Ethics approval}

The animal protocols and care standards of this experiment were accepted and approved by the Committee of Animal Care and Use of the Institute of Subtropical Agriculture, Chinese Academy of Science (Changsha, CAS20190409).

\section{Consent for publication}

Not applicable.

\section{Competing interests}

The authors declare that they have no competing interests.

\section{Author details}

${ }^{1}$ Hunan Provincial Key Laboratory of Animal Nutritional Physiology and Metabolic Process; National Engineering Laboratory for Pollution Control and Waste Utilization in Livestock and Poultry Production; Key Laboratory of Agro-ecological Processes in Subtropical Region; Hunan Provincial Engineering Research Center for Healthy Livestock and Poultry Production; Scientific Observing and Experimental Station of Animal Nutrition and Feed Science in South-Central, Ministry of Agriculture, Institute of Subtropical Agriculture, Chinese Academy of Sciences, Changsha, Hunan 410125, China. ${ }^{2}$ College of Animal Science, South China Agricultural University, Guangzhou, Guangdong 510642, China; ${ }^{3}$ Key Laboratory of Plant Resources/Beijing Botanical Garden, Institute of Botany, Chinese Academy of Sciences, Beijing 100093, China.

\section{References}

1. Circu ML, Aw TY. Intestinal redox biology and oxidative stress. Semin Cell \& Dev Biol. 2012; 23:729737. 
2. Zheng P, Yu B, He J, Yu J, Mao XB, Luo YH Luo JQ, Huang ZQ, Tian G, Zeng QF et al. Arginine metabolism and its protective effects on intestinal health and functions in weaned piglets un,der oxidative stress induced by diquat. Br J Nutr. 2017; 117:1495-1502.

3. Askew EW. Environmental and physical stress and nutrient requirements. Am J Clin Nutr. 1995; 61:631S-637S.

4. Smith F, Clark JE, Overman BL, Tozel CC, Huang JH, Rivier JE, Blikslager AT, Moeser AJ. Early weaning stress impairs development of mucosal barrier function in the porcine intestine. Am J Physiol Gastr L. 2010; 298:G352-363.

5. He QH, Tang HR, Ren PP, Kong XF, Wu GY, Yin YL, Wang YL. Dietary supplementation with I-arginine partially counteracts serum metabonome induced by weaning stress in piglets. J Proteome Res. 2011; 10:5214-5221.

6. Geisert RD, Lucy MC, Whyte JJ, Ross JW, Mathew DJ. Cytokines from the pig conceptus: roles in conceptus development in pigs. J Anim Sci Biotechno. 2014; 5:51.

7. May KD, Wells JE, Maxwell CV, Oliver WT. Granulated lysozyme as an alternative to antibiotics improves growth performance and small intestinal morphology of 10-day-old pigs. J Anim Sci. 2012; 90:1118-1125.

8. Wang L, Muxin G, Nishida H, Shirakawa C, Sato S, Konishi T. Psychological stress-induced oxidative stress as a model of sub-healthy condition and the effect of TCM. Evid Based Compl Alt Med. 2007; 4:195-202.

9. Chinese Pharmacopoeia Commission. Pharmacopoeia of the People's Republic of China. Chemical Industry Publishing House, Beijing, 2015; 160e161.

10. Lin HC, Ding HY, Ko FN, Teng CM, Wu YC. Aggregation inhibitory activity of minor acetophenones from Paeonia species. Planta Med. 1999; 65:595-599.

11. Rho S, Chung HS, Kang M, Lee E, Cho C, Kim H, Park S, Kim HY, Hong M, Shin MJB et al: Inhibition of Production of Reactive Oxygen Species and Gene Expression Profile by Treatment of Ethanol Extract of Moutan Cortex Radicis in Oxidative Stressed PC12 Cells. Biol Pharm Bull. 2005; 28:661-666.

12. Kim J, Lee H, Lee Y, Oh BG, Cho C, Kim Y, Shin M, Hong M, Jung SK, Bae H: Inhibition effects of Moutan Cortex Radicis on secretion of eotaxin in A549 human epithelial cells and eosinophil migration. J Ethnopharmacol. 2007; 114:186-193.

13. Matsuda H, Ohta T, Kawaguchi A, Yoshikawa MJC, Bulletin P. Bioactive Constituents of Chinese Natural Medicines. VI. Moutan Cortex. (2): Structrues and Radical Scavenging Effects of Suffruticosides A, B, C, D, and E, and E and Galloyl-oxypaeoniflorin. Chem Pharm Bull (Tokyo). 2001; 49:69.

14. Koo YK, Kim JM, Koo JY, Kang SS, Bae K, Kim YS, Chung JH, Yunchoi HS. Platelet anti-aggregatory and blood anti-coagulant effects of compounds isolated from Paeonia lactiflora and Paeonia suffruticosa. Pharmazie. 2010; 65:624.

15. Pan LL, Dai M. Paeonol from Paeonia suffruticosa prevents TNF-a-induced monocytic cell adhesion to rat aortic endothelial cells by suppression of VCAM-1 expression. Phytomedicine. 2009; 16:1027- 
1032.

16. Wang YN, Liu MF, Hou WZ, Xu RM, Gao J, Lu AQ, Xie MP, Li L, Zhang JJ, Peng Y, et al. Bioactive Benzofuran Derivatives from Cortex Mori Radicis, and Their Neuroprotective and Analgesic Activities Mediated by mGluRヌ. Molecules (Basel, Switzerland). 2017; 22: 236.

17. Kim JM, Park CH, Park SK, Seung TW, Kang JY, Ha JS, Lee DS, Lee U, Kim DO, Heo HJ, et al. Ginsenoside Re Ameliorates Brain Insulin Resistance and Cognitive Dysfunction in High Fat DietInduced C57BL/6 Mice. J Agric Food Chem. 2017; 65:2719-2729.

18. Himaya SW, Ryu B, Qian ZJ, Kim SK. Paeonol from Hippocampus kuda Bleeler suppressed the neuroinflammatory responses in vitro via NF-KB and MAPK signaling pathways. Toxicol in Vitro. 2012; 26:878-887.

19. Cox LM, Yamanishi S, Sohn J, Alekseyenko AV, Leung JM, Cho I, Kim SG, Li H, Gao Z, Mahana D, et al. Altering the intestinal microbiota during a critical developmental window has lasting metabolic consequences. Cell. 2014; 158:705-721.

20. National Research Council. Nutrient requirements of swine, 11th rev ed. National Academy Press, Washington (DC). 2012.

21. Cao J, Guo FC, Zhang LY, Dong B, Gong LM. Effects of dietary Selenomethionine supplementation on growth performance, antioxidant status, plasma selenium concentration, and immune function in weaning pigs. J Anim Sci Biotechno. 2014; 5:1-7.

22. Liu HN, Tan BE, Huang B, Li JJ, Wang J, Liao P, Guan GP, Ji P, Yin YL. Involvement of calcium-sensing receptor activation in the alleviation of intestinal inflammation in a piglet model by dietary aromatic amino acid supplementation. Br J Nutr. 2018; 120:1-11.

23. Xiong X, Yang HS, Wang XC, Hu Q, Liu CX, Wu X, Deng D, Hou YQ, Nyachoti CM, Xiao DF. Effect of low dosage of chito-oligosaccharide supplementation on intestinal morphology, immune response, antioxidant capacity, and barrier function in weaned piglets. J Anim Sci. 2015; 93:1089-1097.

24. Caporaso JG, Lauber CL, Walters WA, Berg-Lyons D, Huntley J, Fierer N, Owens SM, Betley J, Fraser L, Bauer M. Ultra-high-throughput microbial community analysis on the Illumina HiSeq and MiSeq platforms. ISME J. 2012; 6:1621.

25. Magoč T, Salzberg SL. FLASH: fast length adjustment of short reads to improve genome assemblies. Bioinformatics. 2011; 27:2957-2963.

26. Aßhauer KP, Bernd W, Rolf D, Peter M. Tax4Fun: predicting functional profiles from metagenomic 16S rRNA data. Bioinformatics. 2015; 31:17.

27. Ward T, Larson J, Meulemans J, Hillmann B, Lynch J, Sidiropoulos D, et al. BugBase predicts organism level microbiome phenotypes. BioRxiv [Preprint]. 2017.https:// doi.org/ 10.1101/133462

28. Kong XF, Ji YJ, Li HW, Zhu Q, Blachier F, Geng MM, Chen W, Yin YL. Colonic luminal microbiota and bacterial metabolite composition in pregnant Huanjiang mini-pigs: effects of food composition at different times of pregnancy. Sci Rep-UK. 2016; 6:37224.

29. Fu PK, Yang CY, Tsai TH, Hsieh CL. Moutan cortex radicis improves lipopolysaccharide-induced acute lung injury in rats through anti-inflammation. Phytomedicine : international journal of phytotherapy 
and Phytopharmacol. 2012; 19:1206-1215.

30. Yun CS, Choi YG, Jeong MY, Lee JH, Lim S. Moutan Cortex Radicis inhibits inflammatory changes of gene expression in lipopolysaccharide-stimulated gingival fibroblasts. J Nat Med. 2013; 67:576-589.

31. Xing GQ, Zhang ZY, Liu JQ Hu HH, Sugiura N. Antitumor effect of extracts from moutan cortex on DLD-1 human colon cancer cells in vitro. Mol Med Rep. 2010; 3:57-61.

32. Nabavi SF, Nabavi SM, Mirzaei M, Moghaddam AH. Protective effect of quercetin against sodium fluoride induced oxidative stress in rat's heart. Food Funct. 2012; 3:437-441.

33. Louis XL, Thandapilly SJ, Kalt W, Vinqvist-Tymchuk M, Aloud BM, Raj P, Yu L, Le H, Netticadan T. Blueberry polyphenols prevent cardiomyocyte death by preventing calpain activation and oxidative stress. Food Funct. 2014; 5:1785-1794.

34. Qi GY, Mi YS, Wang YW, Li RN, Huang SX, Li XY, Liu XB. Neuroprotective action of tea polyphenols on oxidative stress-induced apoptosis through the activation of the TrkB/CREB/BDNF pathway and Keap1/Nrf2 signaling pathway in SH-SY5Y cells and mice brain. Food Funct. 2017; 8:4421-4432.

35. You S, Kim GH. Protective effect of Mori Cortex radicis extract against high glucose-induced oxidative stress in PC12 cells. Bioscience, biotechnology, and biochemistry. Biosci Biotechnol Biochem. 2019; 83:1893-1900.

36. Sauer T, Raithel M, Kressel J, Muscat S, Münch G, Pischetsrieder M. Nuclear translocation of NF-kB in intact human gut tissue upon stimulation with coffee and roasting products. Food Funct. 2011; 2:529-540.

37. Wu L, Liao P, He LQ, Ren WK, Yin J, Duan J, Li TJ. Growth performance, serum biochemical profile, jejunal morphology, and the expression of Lutrients transporter genes in deoxynivalenol (DON)challenged growing pigs. BMC Vet Res. 2015; 11:144.

38. Shinbori T, Walczak H, Krammer PH. Activated T killer cells induce apoptosis in lung epithelial cells and the release of pro-inflammatory cytokine TNF-alpha. Eur J Immunol. 2004; 34:1762-1770.

39. Rajapakse N, Kim MM, Mendis E, Kim SK. Inhibition of inducible nitric oxide synthase and cyclooxygenase-2 in lipopolysaccharide-stimulated RAW264.7 cells by carboxybutyrylated glucosamine takes place via down-regulation of mitogen-activated protein kinase-mediated nuclear factor-kappaB signaling. Immunology. 2008; 123:348-357.

40. Sun X, Wang P, Yao LP, Wang W, Gao YM, Zhang J, Fu YJ. Paeonol alleviated acute alcohol-induced liver injury via SIRT1/Nrf2/NF-KB signaling pathway. Environ Toxicol Pharmacol. 2018; 60:110-117.

41. Tripathi A, Debelius J, Brenner DA, Karin M, Loomba R, Schnabl B, Knight R. The gut-liver axis and the intersection with the microbiome. Nat Rev Gastroenterol Hepatol. 2018; 15:397-411.

42. Xiong $X$, Yang HS, Hu XH, Wang XC, Li B, Long LN, Li TJ, Wang JJ, Hou YQ, Wu GY, Yin YL. Differential proteome analysis along jejunal crypt-villus axis in piglets. Front Biosci-Landmark. 2016; 21:343-363.

43. Li Y, Xu FL, Tong X, Chen RN, Shen CY, Liang TT, Chu QP, Zhou B. Effects of Macleaya cordata extract on small intestinal morphology and gastrointestinal microbiota diversity of weaned pigs. Livest Sci. 2020; $237: 9$. 
44. Rowlands B, Soong C, Gardiner K. The gastrointestinal tract as a barrier in sepsis. Brit Med Bull. 1999; 55:196-211.

45. Müller SL, Portwich M, Schmidt A, Utepbergenov DI, Huber O, Blasig IE, Krause G. The tight junction protein occludin and the adherens junction protein alpha-catenin share a common interaction mechanism with ZO-1. J Biol Chem. 2005; 280:3747-3756.

46. Chen L, Li L, Han Y, Lv B, Zou SZ, Yu Q. Tong-fu-li-fei decoction exerts a protective effect on intestinal barrier of sepsis in rats through upregulating ZO-1/occludin/claudin-1 expression. J Pharmacol Sci. 2020; 143:89-96.

47. Wu J, Yang CL, Sha YK, Wu Y, Liu ZY, Yuan Z-H, Sun ZL. Koumine Alleviates LipopolysaccharideInduced Intestinal Barrier Dysfunction in IPEC-J2 Cells by Regulating Nrf2/NF-KB Pathway. Am J Chinese Med. 2020; 48:1-16.

48. Hughes RL, Marco ML, Hughes JP, Keim NL, Kable ME. The Role of the Gut Microbiome in Predicting Response to Diet and the Development of Precision Nutrition Models-Part I: Overview of Current Methods. Adv Nutr. 2019; 10:953-978.

49. Magnusson KR, Hauck L, Jeffrey BM, Elias V, Humphrey A, Nath R, Perrone A, Bermudez LE. Relationships between diet-related changes in the gut microbiome and cognitive flexibility. Neuroscience. 2015; 300:128-140.

50. Guido S, Venema K. Gut microbiota and obesity: Involvement of the adipose tissue. J Funct Foods. $2015 ; 14: 407-423$.

51. Huang GP, Li XQ, Lu D, Liu S, Suo X, Li QY, Li N. Lysozyme improves gut performance and protects against enterotoxigenic Escherichia coli infection in neonatal piglets. Vet Res. 2018; 49:20.

52. Strandwitz P, Kim KH, Terekhova D, Liu JK, Sharma A, Levering J, McDonald D, Dietrich D, Ramadhar TR, Lekbua A, et al. GABA-modulating bacteria of the human gut microbiota. Nat Microbiol. 2019; 4:396-403.

53. Su YT, Chen XJ, Liu M, Guo XH. Effect of three lactobacilli with strain-specific activities on the growth performance, faecal microbiota and ileum mucosa proteomics of piglets. J Anim Sci Biotechno. 2017; 8:52.

54. Turnbaugh PJ, Ley RE, Mahowald MA, Magrini V, Mardis ER, Gordon JI. An obesity-associated gut microbiome with increased capacity for energy harvest. Nature. 2006; 444:1027-1031.

55. Corrêa-Oliveira R, Fachi JL, Vieira A, Sato FT, Vinolo MAR. Regulation of immune cell function by short-chain fatty acids. Clin Transl Immunology. 2016; 5:e73-e73.

56. Lu J, Turnbull L, Burke CM, Liu M, Carter DA, Schlothauer RC, Whitchurch CB, Harry EJ. Manuka-type honeys can eradicate biofilms produced by Staphylococcus aureus strains with different biofilmforming abilities. PeerJ. 2014; 2:e326.

\section{Figures}


(A)
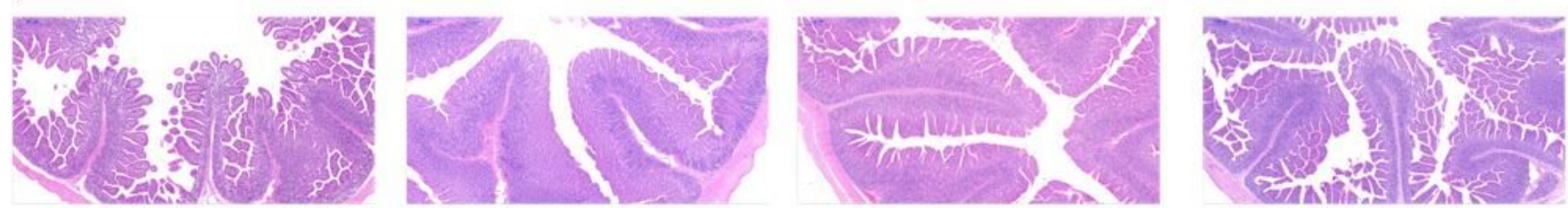

(B)

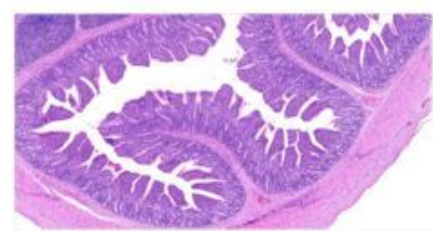

CON

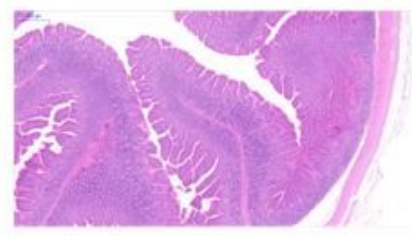

LMC

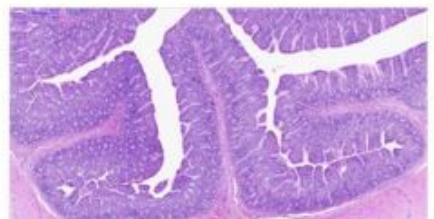

MMC

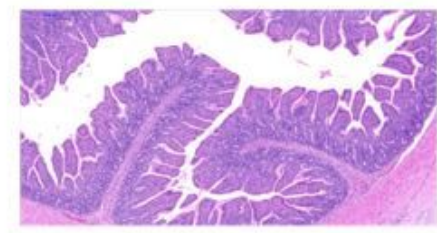

HMC

\section{Figure 1}

The intestinal morphology was histologically analyzed by hematoxylin and eosin (HE, $500 \mu \mathrm{m})$. (A) Jejunum, (B) Ileum. CON, control group, basal diet without antibiotics; LMC, the control diet $+2000 \mathrm{mg} / \mathrm{kg}$ Moutan cortex radicis; MMC, the control diet $+4000 \mathrm{mg} / \mathrm{kg}$ Moutan cortex radicis; HMC, the control diet + $8000 \mathrm{mg} / \mathrm{kg}$ Moutan cortex radicis. 


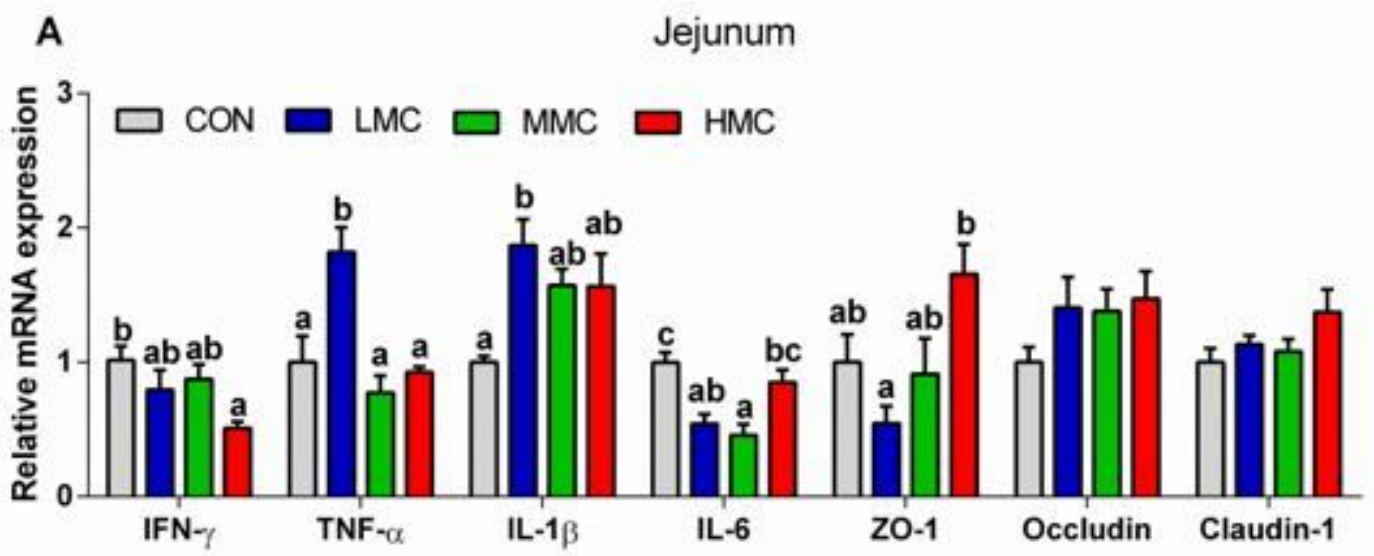

B $\quad$ lleum
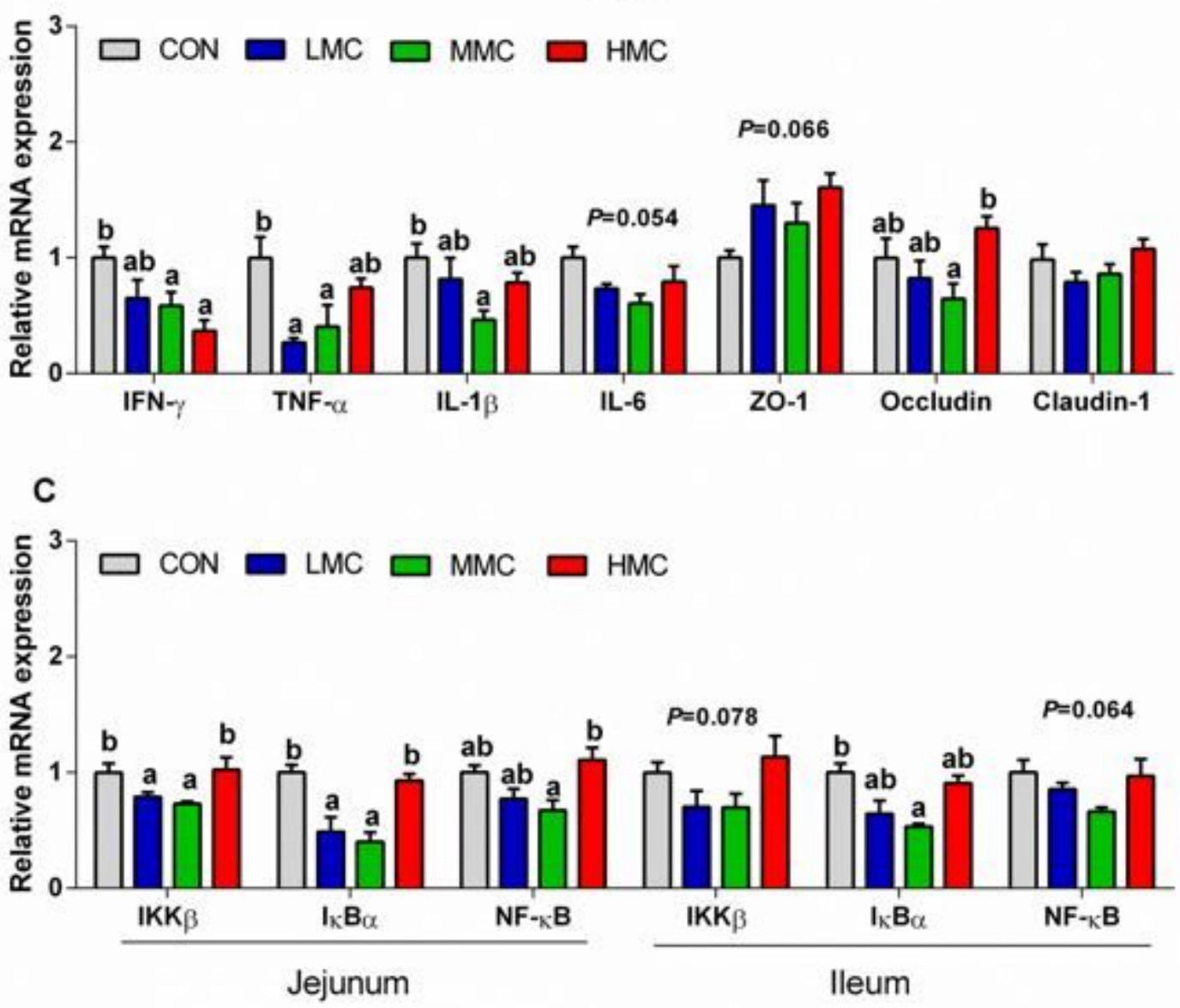

Figure 2

Gene expression levels associated with the proinflammatory factors (IFN- $\gamma$, TNF- $\alpha$, IL-1ß and IL-6) and tight junction proteins (ZO-1, occludin and claudin-1) of jejunum (A) and ileum (B), and NF-KB signaling pathway in the jejunum and ileum tissues $(C)$ of pigs fed the Moutan cortex radicis diet. CON, control group, basal diet without antibiotics; LMC, the control diet $+2000 \mathrm{mg} / \mathrm{kg}$ Moutan cortex radicis; MMC, the control diet $+4000 \mathrm{mg} / \mathrm{kg}$ Moutan cortex radicis; HMC, the control diet $+8000 \mathrm{mg} / \mathrm{kg}$ Moutan cortex 
radicis. Data are expressed as means \pm SEM $(n=6)$. Means within a row with different superscripts are significantly different $(P<0.05)$.
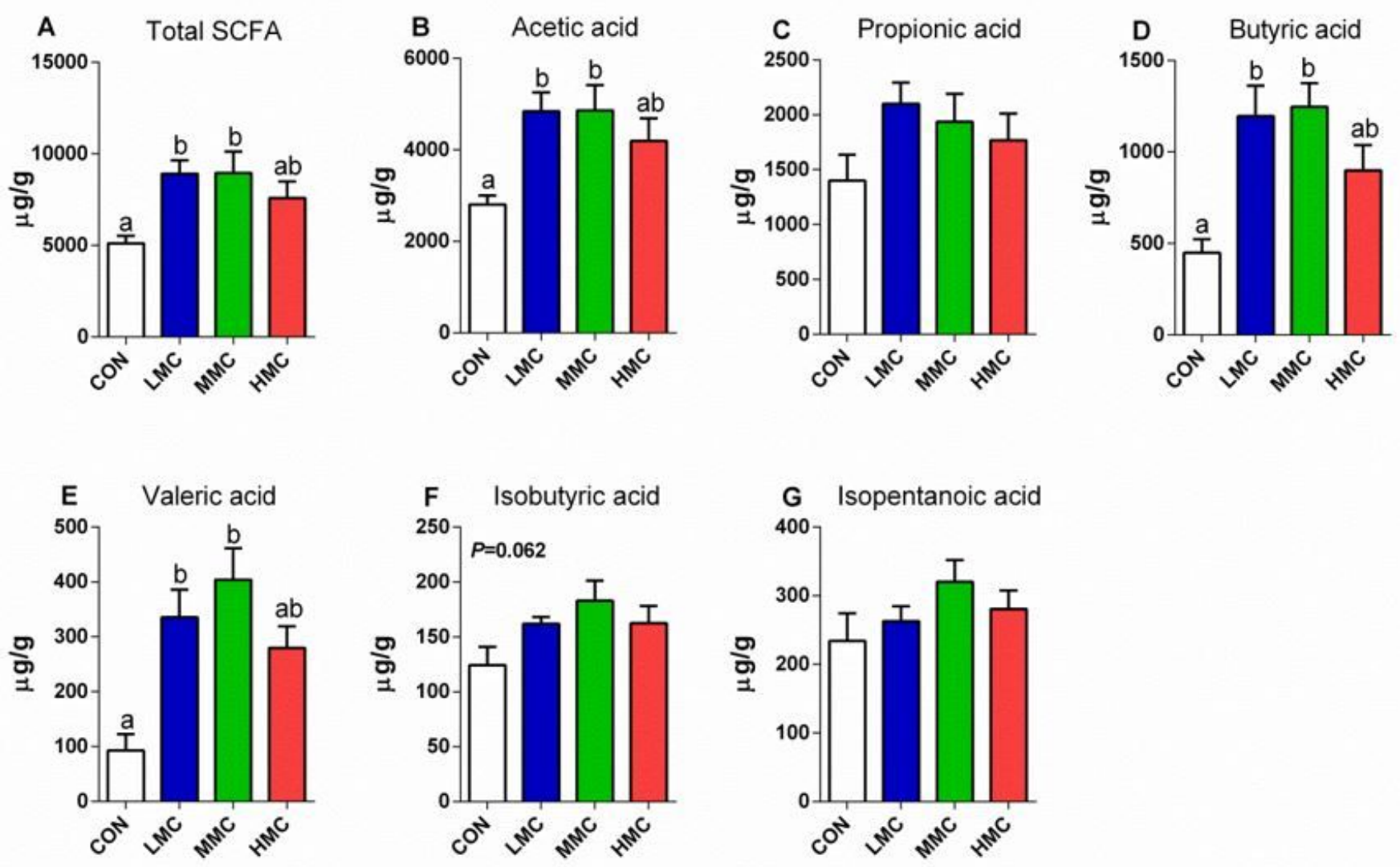

\section{Figure 3}

Total SCFAs (A), acetic acid (B), propionic acid (C), butyric acid (D), valeric acid (E), isobutyric acid (F), and isopentanoic acid $(G)$ concentrations in colonic contents of pigs fed the Moutan cortex radicis diet for 3 wk. CON, control group, basal diet without antibiotics; LMC, the control diet $+2000 \mathrm{mg} / \mathrm{kg}$ Moutan cortex radicis; $\mathrm{MMC}$, the control diet $+4000 \mathrm{mg} / \mathrm{kg}$ Moutan cortex radicis; $\mathrm{HMC}$, the control diet +8000 $\mathrm{mg} / \mathrm{kg}$ Moutan cortex radicis. Data are expressed as means $\pm \mathrm{SEM}(\mathrm{n}=8)$. Means within a row with different superscripts are significantly different $(P<0.05)$. 
A

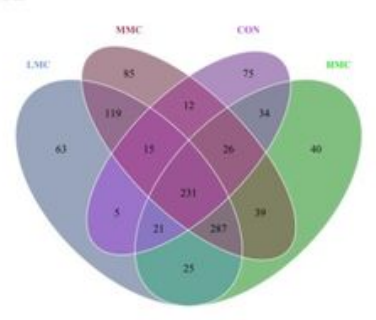

C

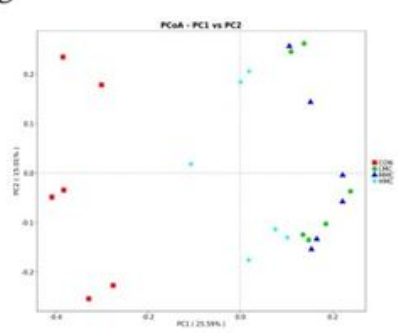

D

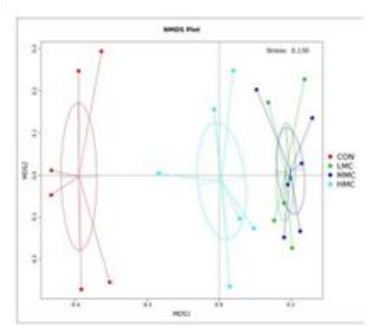

B
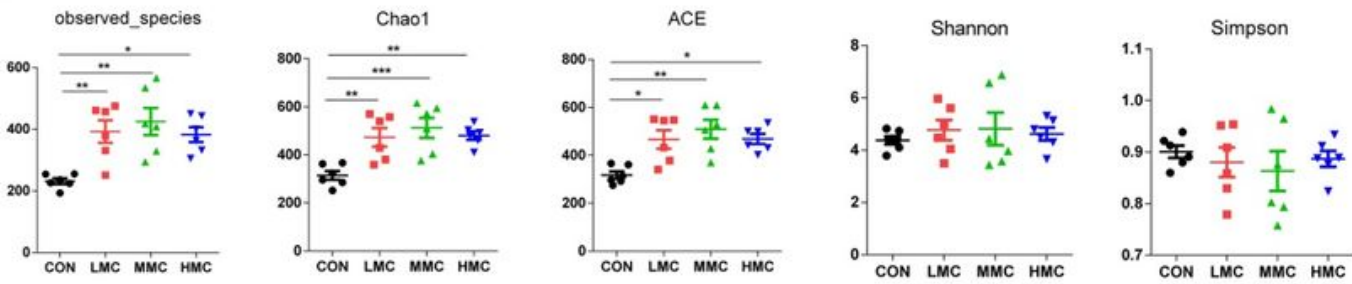

E
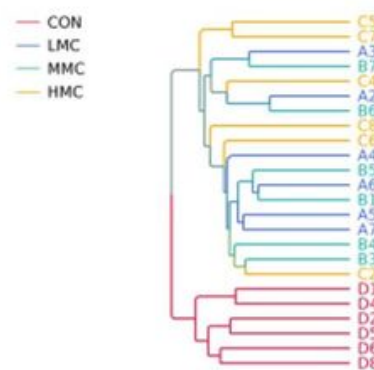

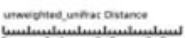
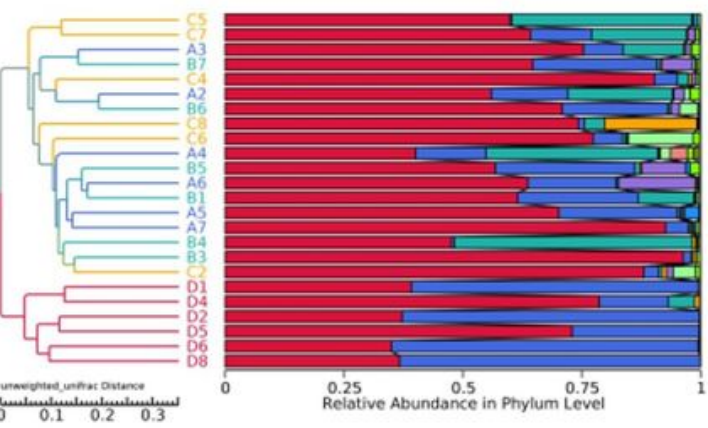

Firmicutes

Bacteroidetes

Actinobacteria

Spirochaetes

unidentified Bacteri

Deferribacteres

Euryarchaeota

Tenericutes

$\square$ Verrucomicrobia

$\square$ others

F

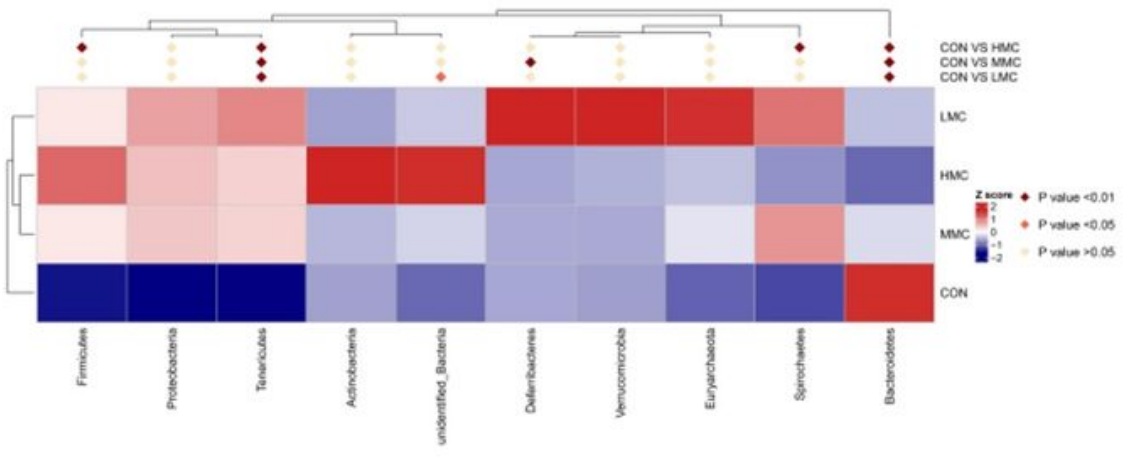

Figure 4

Effect of dietary Moutan cortex radicis on the colonic microbiota diversity and composition in the pigs. (A) A Venn diagram illustrating the overlaps of OTUs in the gut microbiota; (B) The microbial alpha diversity indexs (Observed-species, Chao1, Shannon, Simpson, ACE) were calculated using the mothur program; (C) Principal coordinate analysis (PCoA); (D) non-metric multidimensional scaling (NMDS) analysis; (E) unweighted unifrac cluster tree based on Unweighted Pair-group Method with Arithmetic 
Mean (UPGMA) analysis; (F) The significant different species among groups based on MetaStat analysis. CON, control group, basal diet without antibiotics; LMC, the control diet $+2000 \mathrm{mg} / \mathrm{kg}$ Moutan cortex radicis; $\mathrm{MMC}$, the control diet $+4000 \mathrm{mg} / \mathrm{kg}$ Moutan cortex radicis; $\mathrm{HMC}$, the control diet $+8000 \mathrm{mg} / \mathrm{kg}$ Moutan cortex radicis. Data are expressed as means \pm SEM $(n=6)$. ${ }^{\star} P<0.05,{ }^{\star *} P<0.01$ and ${ }^{\star \star \star} P<<$ 0.001 .
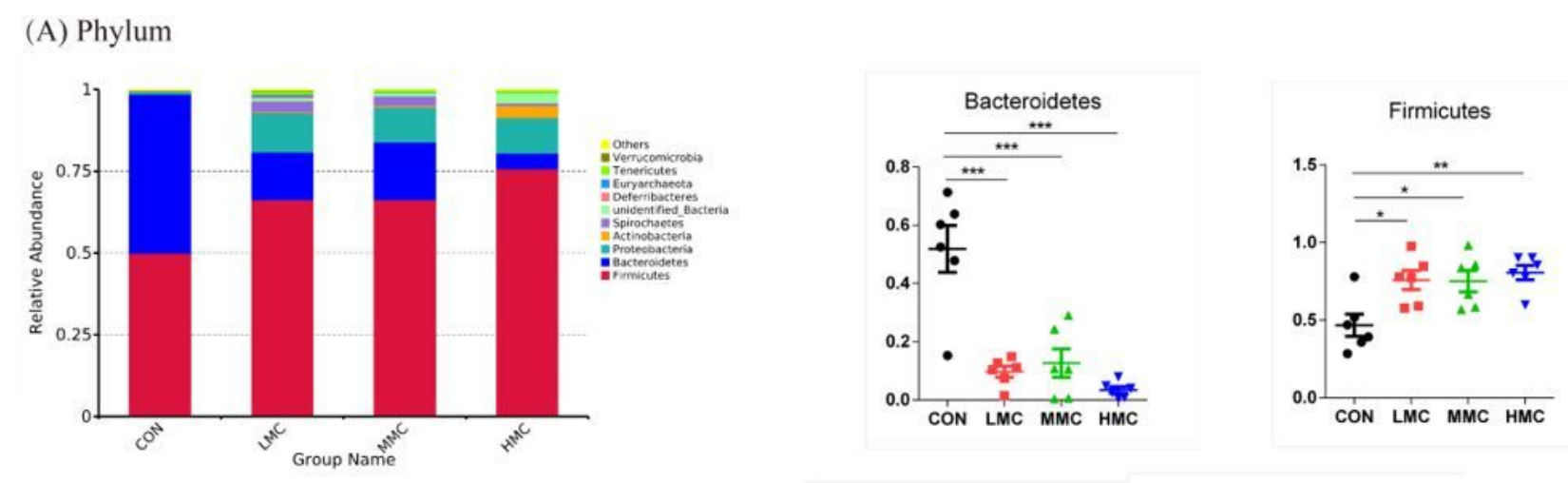

(B) Genus
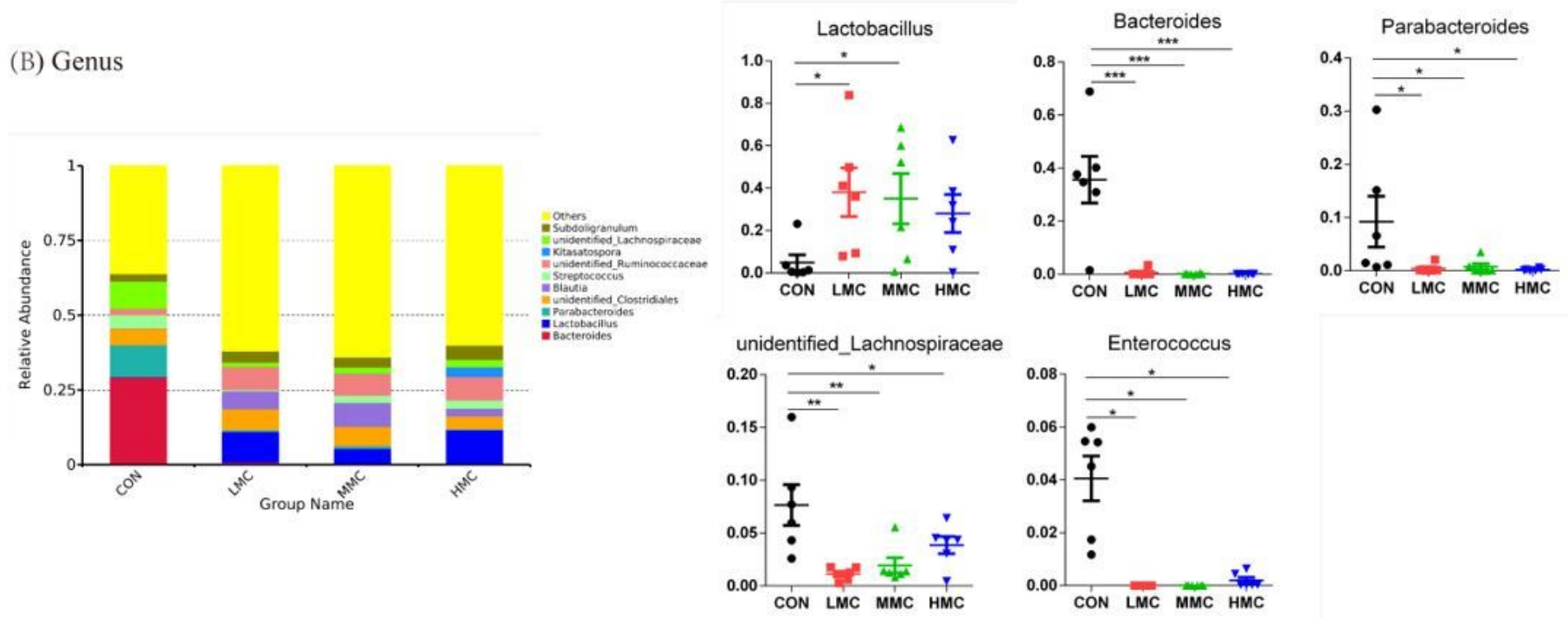

Figure 5

Effects of dietary Moutan cortex radicis on microbial composition at the phylum and genus levels of growing pigs. (A) Relative contribution of the top 10 phylum in each group (left) and the relative abundance of significantly different microorganisms (right); (B) Relative contribution of the top 10 genus in each group (left) and the relative abundance of significantly different microorganisms (right). CON, control group, basal diet without antibiotics; LMC, the control diet $+2000 \mathrm{mg} / \mathrm{kg}$ Moutan cortex radicis; $\mathrm{MMC}$, the control diet $+4000 \mathrm{mg} / \mathrm{kg}$ Moutan cortex radicis; $\mathrm{HMC}$, the control diet $+8000 \mathrm{mg} / \mathrm{kg}$ Moutan cortex radicis. Data are expressed as means \pm SEM $(n=6) . * P<0.05,{ }^{*} \mathrm{P}<0.01$ and ${ }^{\star * *} P<0.001$. 

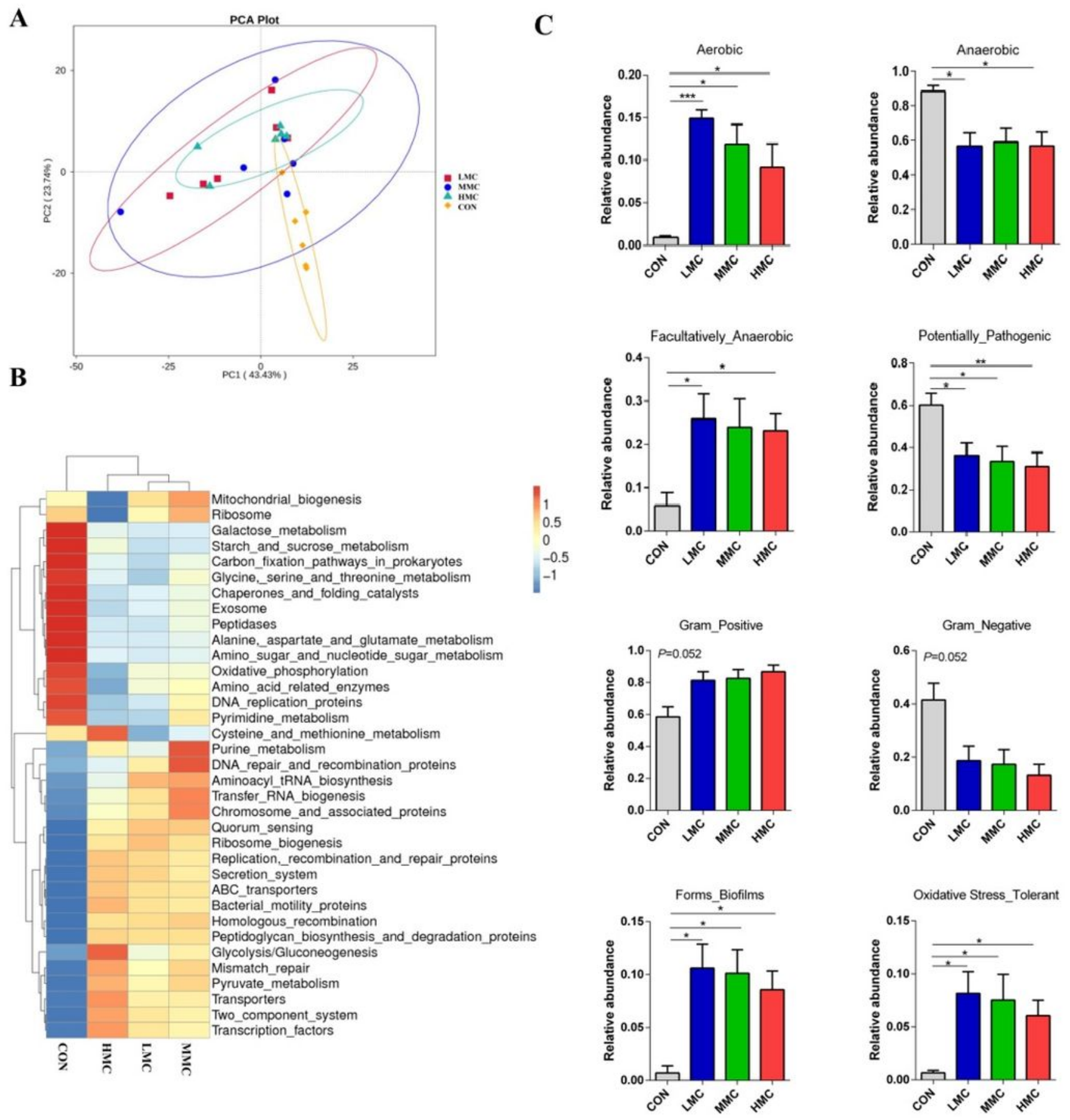

\section{Figure 6}

Dietary supplementation of Moutan cortex radicis altered the metabolic functions and phenotypes of colonic microbiota in the pigs. (A) Principal components analysis (PCA) of functional profiles in the gut microbiota; (B) The heatmap tree based on different metabolism related pathway at KEGG level 3; (C) The metabolic phenotypes prediction were compared using BugBase online (https://bugbase.cs.umn.edu/). The relative abundances of discrete phenotype was performed using pair-wise Mann-Whitney U tests. 
Data are expressed as means \pm SEM $(n=6)$. CON, control group, basal diet without antibiotics; LMC, the control diet $+2000 \mathrm{mg} / \mathrm{kg}$ Moutan cortex radicis; MMC, the control diet $+4000 \mathrm{mg} / \mathrm{kg}$ Moutan cortex radicis; $\mathrm{HMC}$, the control diet $+8000 \mathrm{mg} / \mathrm{kg}$ Moutan cortex radicis. ${ }^{*} \mathrm{P}<0.05$ and $* * \mathrm{P}<0.01$.

A

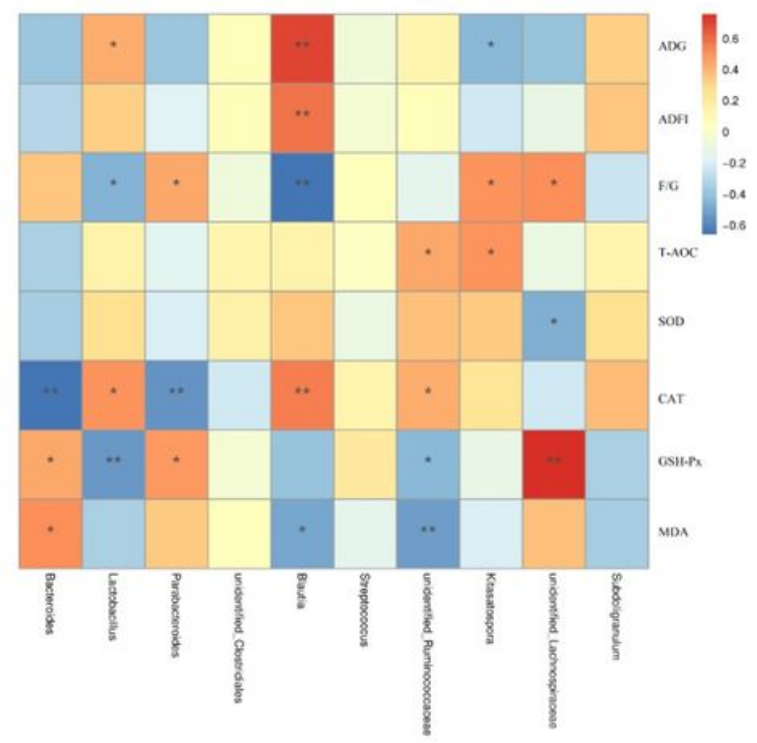

B

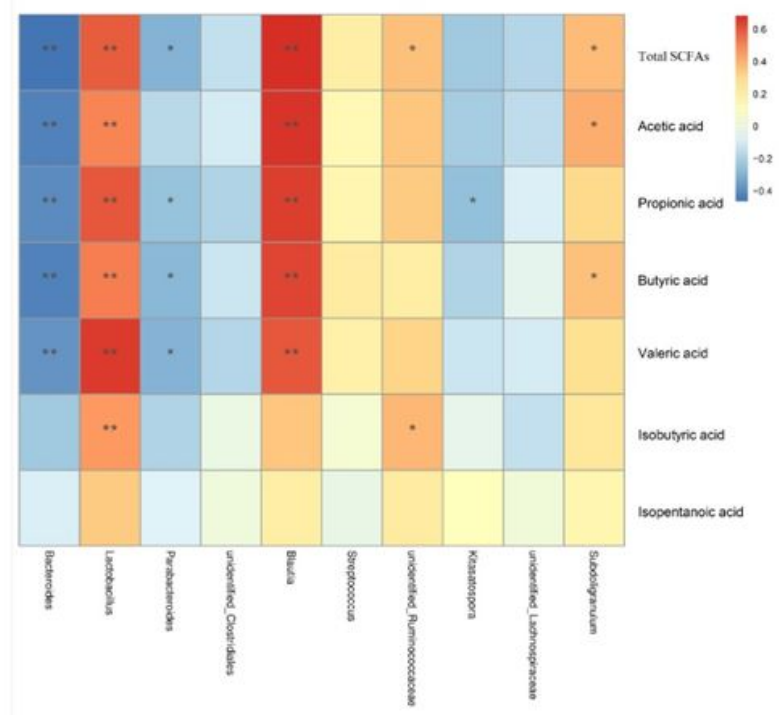

\section{Figure 7}

Heatmap of the Spearman r correlations analysis. Spearman's correlation coefficients between colonic microbiota and growth and serum antioxidant parameters (A), and colonic SCFA contents (B). ${ }^{*}<0.05$ and $* * P<0.01$. 